\title{
Effectiveness Research in the Evolving HCV Landscape
}

\author{
Lisa I. Backus • Pamela S. Belperio
}

Published online: 5 September 2014

(C) Springer Science+Business Media New York (Outside the USA) 2014

As antiviral therapy for chronic hepatitis $\mathrm{C}$ virus (HCV) infection continues to evolve, understanding the effectiveness of antiviral regimens is critical for making informed treatment decisions for HCV management. While the terms "efficacy" and "effectiveness" are often used interchangeably, they hold different meanings: Efficacy is a measure of the capacity of a treatment to produce the desired effect in a controlled environment, such as in a randomized controlled trial whereas effectiveness describes the actual effect of the treatment in practice [1]. In HCV antiviral clinical trials, like other clinical trials, patients are screened using stringent predetermined criteria, closely monitored, and any treatment deviations must follow detailed protocols. As such, information provided in traditional randomized clinical trials is often limited when applied to clinical practice where variation of patient characteristics, setting, care coordination, and management cannot be controlled. These elements are likely to influence the magnitude of the effect in practice depending on who is treated, how they are treated, which conditions are being treated and other nuances. Effectiveness studies, which examine effects (outcomes) in actual practice, provide practical information to address the "where," "how," and "for whom" a treatment might be recommended depending on the questions addressed, patient population, groups compared, setting, and measured outcomes. Though the

Views expressed here are those of the authors and do not necessarily reflect those of the Department of Veterans Affairs.

\section{I. Backus $(\bowtie) \cdot$ P. S. Belperio}

Office of Public Health/Population Health Program, Department of Veterans Affairs, Veterans Affairs Palo Alto Health Care System, 3801 Miranda Avenue (132), Palo Alto, CA 94304, USA

e-mail: Lisa.Backus@va.gov randomized controlled trial is often held up as the "gold standard" for medical decision making, truly informed decision making requires information obtained from clinical practice.

In this issue of Digestive Diseases and Sciences, Price et al. [2] examine real-world treatment outcomes in a comparative effectiveness study of boceprevir and telaprevir in an insured US HCV-infected population. In this large integrated care setting, those undergoing treatment initiation were frequently cirrhotic and treatment-experienced groups, groups usually underrepresented in clinical trials of boceprevir and telaprevir. Almost a third of patients in this study discontinued treatment prematurely, most often patient-initiated and commonly related to adverse effects. Sustained virological response (SVR) rates were notably lower than reported in clinical trials: $48-54 \%$ for boceprevir-based regimens and $31-67 \%$ for telaprevir-based regimens depending on prior $\mathrm{HCV}$ treatment experience and stage of liver disease. The findings underscore the differences between "real-world" HCV care experiences and clinical trials. The observed SVR rates serve as further documentation of the decrement in effectiveness when moving from the clinical trial to clinical practice.

With current advances in HCV treatment and approval of newer, better tolerated, and less complex regimens, the use of boceprevir and telaprevir regimens is expected to be greatly reduced. Yet, results from this study and other comparative effectiveness studies are still useful. The differences observed in this study with regards to patient characteristics, early treatment discontinuations, adverse effects, and lower SVR rates reflect the differences between clinical trials and clinical practice. Perhaps more importantly, it demonstrates that providers, patients, and payers need to appropriately temper expectations about 
outcomes when new medications are approved and used in real-world settings.

This study brings to light another essential issue regarding for whom $\mathrm{HCV}$ treatment is being initiated. Compared to the overall pool of treatment-eligible patients in this cohort, those that initiated treatment were more likely to be cirrhotic, which the authors suggest was due to treatment prioritization based partly on illness severity. Despite the urgency to treat patients with more advanced $\mathrm{HCV}$ disease in clinical practice - and the reality that this population represents a substantial proportion of those who are actually being treated-clinical trials often include very few such patients and thus applicability of clinical trial outcomes to these key populations is limited. For example, in clinical trials of currently approved direct-acting antivirals for genotype 1 infection, cirrhosis was present in only 4-17\% of sofosbuvir patients enrolled, $10-15 \%$ of simeprevir patients, 9-11\% of boceprevir patients, and 6-23\% of telaprevir patients, with most study arms having less than 30 cirrhotic patients included [3-10]. Effectiveness studies may thus provide the only data needed to predict outcomes in these challenging populations where clinical trial data is lacking.

Results of this effectiveness study and other similar studies further highlight difficulties of completing $\mathrm{HCV}$ treatment in "real-world" settings. Without the additional resources that generally accompany clinical trial participation, patients, and providers may be less willing or able to endure adverse effects, complex treatment regimens, and frequent clinic visits, culminating in a lower threshold for stopping therapy. This has been particularly true for those with cirrhosis who are more likely to experience adverse effects and less likely to tolerate therapy, thus leading to early treatment discontinuation [11, 12]. So few patients with advanced HCV disease have been included in HCV antiviral clinical trials, the extent of adverse effects, and poor tolerability in patients with cirrhosis had not been recognized before these effectiveness studies.

Consistently lower SVR rates have been reported in real-world cohorts with peginterferon/ribavirin-based regimens and with boceprevir- and telaprevir-based regimens. Historically, SVR rates in genotype 1 patients treated with peginterferon/ribavirin dual therapy in actual clinical practice have been 15-25\% lower than reported in clinical trials $[13,14]$. As reported by Price et al. and noted in other "real-world" cohorts evaluating boceprevir- and telaprevirbased regimens, overall SVR rates were 4-20\% lower than those reported in clinical trials [15-18]. The observed differences in SVR rates likely reflect the diverse HCVinfected population treated in "real-world" practice, many of whom would never meet stringent clinical trial screening criteria and would never qualify for clinical trial enrollment due to existing comorbidities, laboratory abnormalities, or social issues. Such factors highlight the challenges associated with $\mathrm{HCV}$ treatment in routine clinical practice and may explain why clinical trial results do not always translate to other $\mathrm{HCV}$ care settings. Thus, providers, patients, and payers should have realistic expectations that SVR rates may be lower than predicted from clinical trials and recognize that comparative effectiveness outcomes may better reflect the outcomes that will be attained in the populations actually being treated.

Given the extraordinary costs of newer agents and the associated burden on the healthcare system, adjusting costeffectiveness models based on these comparative effectiveness data could potentially identify specific patient populations where boceprevir or telaprevir regimens may be comparable to newer HCV antiviral regimens. This may be particularly relevant as payers grapple with economic realities which may necessitate continued use of boceprevir or telaprevir, particularly in resource-constrained settings. It is conceivable that insurers may use tiered systems for managing costs which could include boceprevir- or telaprevir-based regimens.

The rapidly changing environment surrounding $\mathrm{HCV}$ antivirals and the FDA breakthrough therapy designation granted to several HCV agents including sofosbuvir, sofosbuvir/ledipasvir, daclatasvir, asunaprevir, and the triple drug direct acting combination ABT-450/r-ombitasvir and dasabuvir, means medications are being approved much more quickly and on the basis of preliminary clinical evidence. In such an environment, providers, patients, and payers will often be faced with making decisions on the basis of small or incomplete clinical data. By the time sufficient numbers of patients receiving a particular regimen can be accrued in clinical practice in order to assess effectiveness, that regimen will be supplanted by newer medications. We have seen this already with boceprevir and telaprevir regimens. With the imminent expected approval of new agents, we are likely to see this same phenomenon with simeprevir and some sofosbuvir-based regimens as well. Given this rapid pace and the number of HCV antiviral agents currently under investigation, not to mention appealing off-label combinations, it will be difficult to produce timely comparative effectiveness data before the field has moved on. By the time comparative effectiveness data can be evaluated, many will view it as outdated. Yet, "real-world" experiences are essential to provide practical information that may better inform $\mathrm{HCV}$ treatment decisions in this highly segmented drug market.

In summary, the comparative effectiveness study by Price et al. represents an important high-quality evaluation that explores outcomes with direct-acting agents in a "realworld" community-based setting. It highlights practical experiences, key issues, and outcomes that are not always sufficiently examined in clinical trials but will continue to 
be relevant to future $\mathrm{HCV}$ regimens. It provides the opportunity to assess cost-effectiveness more accurately given the economic realities with newer $\mathrm{HCV}$ agents that may preclude their use. These results serve as a reminder to the HCV community that since efficacy and effectiveness are not interchangeable, the differences between clinical trials and clinical practice are many, are important, and should not be overlooked.

Acknowledgments Drs. Backus and Belperio are supported by the Department of Veterans Affairs.

Conflict of interest None.

\section{References}

1. Schumock GT, Pickard AS. Comparative effectiveness research: relevance and applications to pharmacy. Am J Health Syst Pharm. 2009;66:1278-1286.

2. Price JC, Murphy RC, Shvachko VA, Pauly MP, Manos MM. Effectiveness of telaprevir and boceprevir triple therapy for patients with hepatitis $\mathrm{C}$ virus infection in a large integrated care setting. Dig Dis Sci. (Epub ahead of print). doi:10.1007/s10620014-3294-0.

3. Sulkowski MS, Naggie S, Lalezari J, et al. Sofosbuvir and ribavirin for hepatitis $\mathrm{C}$ in patients with HIV coinfection. JAMA. 2014;312:353-361.

4. Lawitz E, Mangia A, Wyles D, et al. Sofosbuvir for previously untreated chronic hepatitis $\mathrm{C}$ infection. $N$ Engl $J$ Med. 2013;368:1878-1887.

5. Forns X, Lawitz E, Zeuzem S, et al. Simeprevir with peginterferon and ribavirin leads to high rates of SVR in patients with HCV genotype 1 who relapsed after previous therapy: a phase 3 trial. Gastroenterology. 2014;146:1669-1679.

6. Manns M, Marcellin P, Poordad F, et al. Simeprevir with pegylated interferon alfa $2 \mathrm{a}$ or $2 \mathrm{~b}$ plus ribavirin in treatment-naive patients with chronic hepatitis $\mathrm{C}$ virus genotype 1 infection (QUEST-2): a randomised, double-blind, placebo-controlled phase 3 trial. Lancet. 2014;384:414-426.
7. Jacobson IM, McHutchison JG, Dusheiko G, et al. Telaprevir for previously untreated chronic hepatitis $\mathrm{C}$ virus infection. $N$ Engl $J$ Med. 2011;364:2405-2416.

8. Zeuzem S, Andreone P, Pol S, et al. Telaprevir for retreatment of HCV infection. N Engl J Med. 2011;364:2417-2428.

9. Poordad F, McCone J Jr, Bacon BR, et al. Boceprevir for untreated chronic HCV genotype 1 Infection. $N$ Engl J Med.. 2011;364:1195-1206.

10. Bacon BR, Gordon SC, Lawitz E, et al. Boceprevir for previously treated chronic HCV genotype 1 infection. $N$ Engl $J$ Med. 2011;364:1207-1217.

11. Belperio PS, Hwang EW, Thomas IC, Mole LA, Cheung RC, Backus LI. Early virologic responses and hematologic safety of direct-acting antiviral therapies in veterans with chronic hepatitis C. Clin Gastroenterol Hepatol. 2013;11:1021-1027.

12. Hézode C, Fontaine H, Dorival C, et al. Effectiveness of telaprevir or boceprevir in treatment-experienced patients with $\mathrm{HCV}$ genotype 1 infection and cirrhosis. Gastroenterology. 2014;147: 132-142.

13. McHutchison JG, Lawitz EJ, Shiffman ML, et al. Peginterferon alfa-2b or alfa-2a with ribavirin for treatment of hepatitis $\mathrm{C}$ infection. N Engl J Med. 2009;361:580-593.

14. Fried MW, Shiffman ML, Reddy KR, et al. Peginterferon alfa-2a plus ribavirin for chronic hepatitis C virus infection. $N$ Engl $J$ Med. 2002;347:975-982.

15. Ioannou GN, Beste LA, Green PK. Similar effectiveness of boceprevir and telaprevir treatment regimens for hepatitis $\mathrm{C}$ virus infection, based on a nationwide study of Veterans. Clin Gastroenterol Hepatol. 2014;12:1371-1380.

16. Backus LI, Belperio PS, Shahoumian TA, Cheung R, Mole LA. Comparative effectiveness of the hepatitis $\mathrm{C}$ virus protease inhibitors boceprevir and telaprevir in a large U.S. cohort. Aliment Pharmacol Ther. 2014;39:93-103.

17. Wehmeyer MH, Eissing F, Jordan S, et al. Safety and efficacy of protease inhibitor based combination therapy in a single-center "real-life" cohort of 110 patients with chronic hepatitis C genotype 1 infection. BMC Gastroenterol.. 2014;14:87.

18. Maasoumy B, Port K, Deterding K, et al. Limited effectiveness and safety profile of protease inhibitor-based triple therapy against chronic hepatitis $\mathrm{C}$ in a real-world cohort with a high proportion of advanced liver disease. Eur J Gastroenterol Hepatol. 2014;26:836-845. 